\title{
Effect of properties of the $N, N$-dimethylformamide + methanol and $N, N$-dimethylformamide + water mixtures on the solution enthalpy of cyclic ethers in these mixtures at $298.15 \mathrm{~K}$
}

\author{
Małgorzata Jóźwiak $^{1}$ - Henryk Piekarski ${ }^{1}$ - Aleksandra Bińkowska ${ }^{1}$ • \\ Katarzyna Łudzik ${ }^{1}$
}

Received: 29 February 2016/Accepted: 21 June 2016/Published online: 5 July 2016

(C) The Author(s) 2016. This article is published with open access at Springerlink.com

\begin{abstract}
The enthalpies of solution of cyclic ethers [1,4dioxane, 12-crown-4 (12C4), 15-crown-5 (15C5) and 18-crown-6 (18C6)] in $\mathrm{N}, \mathrm{N}$-dimethylformamide + methanol $(\mathrm{DMF}+\mathrm{MeOH})$ mixtures have been measured at $298.15 \mathrm{~K}$. On the basis of the obtained data, the effect of the acid-base and structure-energetic properties of the $\mathrm{DMF}+\mathrm{MeOH}$ mixtures on the enthalpy of solution of cyclic ethers in these mixtures has been analyzed. The results have been compared with analogous data concerning the cyclic ethers in $\mathrm{N}, \mathrm{N}$-dimethylformamide + water $(\mathrm{DMF}+\mathrm{W})$ mixtures.
\end{abstract}

Keywords Cyclic ethers $\cdot N, N$-Dimethylformamide + methanol mixtures $\cdot N, N$-Dimethylformamide + water mixtures $\cdot$ Enthalpy of solution

\section{Introduction}

Crown ethers are very well-known and interesting compounds widely used in biology, medicine and chemistry. Because of their structure, they can form complexes with cations [1,2] and small organic molecules [3-6]. Crown ethers are among the most popular catalysts used in the organic synthesis technique called phase-transfer catalysis [7-10] and in the nucleophilic substitution [11]. The use of crown ethers is closely connected with their interaction with the molecules of the solvent used for investigations. The latter, in turn, depend on the properties of pure or

Małgorzata Jóźwiak

mjozwiak@uni.lodz.pl

1 Department of Physical Chemistry, Faculty of Chemistry, University of Lodz, Pomorska 165, 90-236 Lodz, Poland mixed solvents. Very often the course of chemical reactions and their mechanism is dependent on the solvating properties of solvents; thus, the selection of solvent for chemical reactions plays a very important role. For this reason, the knowledge how cyclic ethers interact with organic solvent molecules is of paramount importance. Many papers have dealt with the effect of the properties of pure [12-15] and mixed (organic + organic and organic + water) solvents on physical and chemical processes in solution [16, 17].

In our research, we are looking for the relationship between the dissolution enthalpy of cyclic ethers and different properties of mixed solvents. We have studied the dissolution enthalpy of cyclic ethers in various mixed solvents [18-26], with particular attention paid to hydrophobic hydration of the solutes [23-25]. In this research, the significant role has been played by the solutions in $N, N$-dimethylformamide + water mixed solvent $(\mathrm{DMF}+\mathrm{W})[23,24]$. It is as, in opinion of some authors $[27,28]$, in these mixtures the energetic effects of hydrophobic hydration and of hydrophilic hydration of the DMF molecule are similar in their magnitude and they almost compensate one another [27, 28]. For this reason, the mentioned mixtures are very suitable for thermochemical examination of hydrophobic properties of different solutes and the deviations from the additivity of the dissolution enthalpies can serve as a measure of the solute hydrophobic hydration effect.

Besides the hydrophobic hydration effect on the solvation of crown ethers in solution, we have analyzed the effect of energetic properties expressed through the excess enthalpy, effect of structural properties illustrated by volume excess and also effect of the acid-base properties described by the appropriate functions [18]. The latter characteristics, in our opinion, have the fundamental 
significance in such analysis. Despite this, only a few reports concerning the examination of the effect of the acid-base properties of single solvents on chemical and physical processes could be found in the literature [29-32]. Therefore, we have decided to continue our studies on this subject. In earlier works, we examined, from this point of view, the solutions in mixed solvents, where one of the mixture components was water. They were the mixtures of water (W) with organic solvents such as: propan-1-ol $(\mathrm{PrOH})[19,20]$, acetonitrile (AN) [19, 21], acetone (ACN) [22], dimethylsulfoxide (DMSO) [22] and methanol $(\mathrm{MeOH})$ [33].

As it is well known, water is a very important and specific solvent due to its capability for hydrophobic hydration of solutes. This process does not occur in the case of other solvents. Therefore, it seemed to be interesting what would happen when we replace water in the mentioned mixtures by the organic solvent, namely methanol. Methanol belongs to the most popular solvents and similarly to water is amphiprotic and hydrogen-bonded one, but it differs from water in its structure and no effect analogous to the hydrophobic hydration (e.g., solvophobic solvation) was observed in methanolic solutions. In the present paper, we have examined the effect of acid-base and structural-energetic properties of the $\mathrm{DMF}+\mathrm{MeOH}$ mixtures on the enthalpy of dissolution of cyclic ethers in these mixtures and compared the obtained results with the appropriate data for solutions in DMF $+\mathrm{W}$ mixtures.

\section{Experimental}

\section{Materials}

Suppliers, purity, a method of purification and water contents in the compounds used for measurements $(1,4$-dioxane, 12-crown-4, 15-crown-5, 18-crown-6, methanol and $\mathrm{N}, \mathrm{N}$-dimethylformamide) are shown in Table 1.

\section{Methods}

The enthalpy of solution of cyclic ethers in the DMF + $\mathrm{MeOH}$ mixtures was examined at $(298.15 \pm 0.01) \mathrm{K}$ using an "isoperibol"-type calorimeter as described in the literature [36]. The calorimeter was verified on the basis of the standard enthalpy of solution of urea and $\mathrm{KCl}$ (Calorimetric standard US, NBS) in water at $(298.15 \pm 0.01) \mathrm{K}$ $[37,38]$. The mean value of the enthalpy of solution of urea in water obtained by us from seven independent measurements was $(15.31 \pm 0.06) \mathrm{kJ} \mathrm{mol}^{-1}$ (literature data $15.31 \mathrm{~kJ} \mathrm{~mol}^{-1}$ ) [39], $15.28 \mathrm{~kJ} \mathrm{~mol}^{-1}$ [40] and $15.30 \mathrm{~kJ} \mathrm{~mol}^{-1}$ [41] and that for $\mathrm{KCl}$ in water was $(17.55 \pm 0.05) \mathrm{kJ} \mathrm{mol}^{-1}$ (literature data $17.58 \mathrm{~kJ} \mathrm{~mol}^{-1}$ ) $[37,38]$.

The concentrations of cyclic ethers in the mixtures were for: 1,4-dioxane (from 0.00352 to 0.02221 ) $\mathrm{mol} \mathrm{kg}^{-1}$ (the mole per kilogram of solvent), $12 \mathrm{C} 4$ (from 0.00253 to 0.01791 ) $\mathrm{mol} \mathrm{kg}^{-1}, 15 \mathrm{C} 5$ (from 0.00234 to 0.00907 ) $\mathrm{mol} \mathrm{kg}^{-1}$ and $18 \mathrm{C} 6$ (from 0.00167 to $0.00322) \mathrm{mol} \mathrm{kg}^{-1}$. Six to eight independent measurements were performed for each investigation systems. The uncertainties in the measured enthalpies did not exceed \pm $0.5 \%$ of the measured value. No concentration dependence (outside the error limits) of the measured enthalpies of solution was observed within the examined range of cyclic ethers content. For this reason, the standard enthalpy of solution $\Delta_{\text {sol }} H^{\circ}$ was calculated as a mean value of the measured enthalpies (Table 2).

\section{Results and discussion}

For the description of solutions in binary solvent, the enthalpy of transfer $\Delta_{\mathrm{tr}} H^{\circ}$ of the solute from an individual solvent $(\mathrm{S})$ to the mixed solvent $(\mathrm{M}=\mathrm{S}+\mathrm{Y})$ of various compositions is a very convenient function. It allows us to very easily compare the effect of the mixed solvent

Table 1 Materials

\begin{tabular}{|c|c|c|c|c|}
\hline Chemical name & Source & Initial mole fraction purity & Purification method & Mass fraction of water/ppm \\
\hline Urea & Fluka & $>0.995^{\mathrm{a}}$ & $\begin{array}{l}\text { Recrystallization from ethanol and dried } \\
\text { under vacuum to constant mass }\end{array}$ & - \\
\hline $\mathrm{KCl}$ & Sigma-Aldrich & $>0.995^{\mathrm{a}}$ & Dried under vacuum to constant mass & - \\
\hline 1,4-Dioxane & Aldrich & $>0.99^{\mathrm{a}}$ & Used as received & $200^{\mathrm{b}}$ \\
\hline $12 \mathrm{C} 4$ & Fluka & $\geq 0.98^{\mathrm{a}}$ & Dried under vacuum & $700^{\mathrm{b}}$ \\
\hline $15 \mathrm{C} 5$ & Aldrich & $0.98^{\mathrm{a}}$ & Dried under vacuum & $1000^{\mathrm{b}}$ \\
\hline $18 \mathrm{C} 6$ & Fluka & $\geq 0.99^{\mathrm{a}}$ & Dried under vacuum & - \\
\hline $\mathrm{MeOH}$ & Chempur & $>0.998$ & Purification and distillation [34] & $800^{\mathrm{b}}$ \\
\hline DMF & Aldrich & $0.998^{\mathrm{a}}$ & Purification and distillation [35] & $<100^{\mathrm{b}}$ \\
\hline
\end{tabular}

${ }^{a}$ Declared by the supplier

b Determined by Karl Fisher method 
Table 2 Standard enthalpies of solution $\left(\Delta_{\text {sol }} H^{\circ} / \mathrm{kJ} \mathrm{mol}^{-1}\right)$ of cyclic ethers: 1,4-dioxane, 12-crown-4 (12C4), 15-crown-5 (15C5) and 18-crown6 (18C6) in DMF $+\mathrm{MeOH}$ mixtures at $298.15 \mathrm{~K}$ at the pressure $p=0.1 \mathrm{MPa}$

\begin{tabular}{|c|c|c|c|c|c|c|c|c|}
\hline \multirow[t]{2}{*}{$x_{\mathrm{MeOH}}^{\mathrm{a}}$} & \multicolumn{2}{|c|}{ 1,4-Dioxane } & \multicolumn{2}{|c|}{$12 \mathrm{C} 4$} & \multicolumn{2}{|c|}{$15 \mathrm{C} 5$} & \multicolumn{2}{|c|}{$18 \mathrm{C} 6$} \\
\hline & $N^{\mathrm{b}}$ & $\Delta_{\mathrm{sol}} H^{\circ} / \mathrm{kJ} \mathrm{mol}^{-1}$ & $N^{\mathrm{b}}$ & $\Delta_{\mathrm{sol}} H^{\circ} / \mathrm{kJ} \mathrm{mol}^{-1}$ & $N^{\mathrm{b}}$ & $\Delta_{\mathrm{sol}} H^{\circ} / \mathrm{kJ} \mathrm{mol}^{-1}$ & $N^{\mathrm{b}}$ & $\Delta_{\mathrm{sol}} H^{\circ} / \mathrm{kJ} \mathrm{mol}^{-1}$ \\
\hline 0 & 8 & $\begin{array}{l}0.86 \pm 0.06 \\
0.86[25] \\
0.84[42]\end{array}$ & 8 & $\begin{array}{l}-0.35 \pm 0.07 \\
-0.35[23]\end{array}$ & 8 & $\begin{array}{l}-0.37 \pm 0.08 \\
-0.38[24]\end{array}$ & 6 & $\begin{array}{l}33.64 \pm 0.06 \\
33.66[24] \\
33.76[44] \\
34.02[45]\end{array}$ \\
\hline 0.10 & 8 & $0.90 \pm 0.07$ & 8 & $-0.33 \pm 0.08$ & 8 & $-0.22 \pm 0.06$ & 6 & $33.67 \pm 0.07$ \\
\hline 0.20 & 8 & $1.00 \pm 0.07$ & 8 & $-0.28 \pm 0.07$ & & $-0.05^{\mathrm{c}}$ & 6 & $33.70 \pm 0.05$ \\
\hline 0.30 & 8 & $1.15 \pm 0.05$ & 8 & $-0.18 \pm 0.08$ & 8 & $0.16 \pm 0.09$ & 6 & $33.74 \pm 0.06$ \\
\hline 0.40 & 8 & $1.33 \pm 0.06$ & & $-0.08^{\mathrm{c}}$ & 8 & $0.43 \pm 0.09$ & 6 & $33.79 \pm 0.05$ \\
\hline 0.50 & 7 & $1.56 \pm 0.05$ & & $0.02^{\mathrm{c}}$ & 8 & $0.74 \pm 0.08$ & 6 & $33.88 \pm 0.07$ \\
\hline 0.60 & 7 & $1.95 \pm 0.05$ & & $0.12^{\mathrm{c}}$ & 8 & $1.08 \pm 0.07$ & 7 & $34.01 \pm 0.06$ \\
\hline 0.70 & 6 & $2.45 \pm 0.04$ & 8 & $0.21 \pm 0.08$ & 8 & $1.44 \pm 0.07$ & 6 & $34.17 \pm 0.06$ \\
\hline 0.80 & 6 & $3.12 \pm 0.04$ & 8 & $0.30 \pm 0.07$ & 8 & $1.84 \pm 0.08$ & 6 & $34.34 \pm 0.07$ \\
\hline 0.90 & 6 & $3.87 \pm 0.03$ & 8 & $0.41 \pm 0.07$ & 8 & $2.24 \pm 0.06$ & 6 & $34.52 \pm 0.06$ \\
\hline 1 & 6 & $\begin{array}{l}4.73 \pm 0.04 \\
4.28[42]\end{array}$ & 8 & $\begin{array}{l}0.54 \pm 0.06 \\
-0.27[43]\end{array}$ & 8 & $\begin{array}{l}2.64 \pm 0.06 \\
2.65[26]\end{array}$ & 8 & $\begin{array}{l}34.72 \pm 0.07 \\
35.13[44] \\
35.23[45] \\
34.70[46]\end{array}$ \\
\hline
\end{tabular}

\footnotetext{
\pm Standard deviation

a $x_{\mathrm{MeOH}}$ is the mole fraction of $\mathrm{MeOH}$ in the mixtures with DMF

b $N$ is the number of measurements

c The value estimated from the function $\Delta_{\mathrm{sol}} H^{\circ}=f\left(x_{\mathrm{MeOH}}\right)$
}

composition change on the behavior of different solutes (in our case the cyclic ethers) in the same mixture as well as to compare the effect of the cosolvent added (in our case methanol or water) on the properties of solutions of the same solute in different mixed solvents. What is also important is the changes of the transfer enthalpy as a function of solvent composition are the same as the enthalpy of solvation ones (Eq. 1). The transfer enthalpies can be easily calculated as a difference between the standard enthalpy of solution of the solute in the mixture (M) and in the single solvent (S) (Eq. 1).

$$
\begin{aligned}
\Delta_{\text {tr }} H^{\circ} & =\Delta_{\text {solv }} H^{\circ}(\mathrm{M})-\Delta_{\text {solv }} H^{\circ}(\mathrm{S}) \\
& =\Delta_{\text {sol }} H^{\circ}(\mathrm{M})-\Delta_{\text {sol }} H^{\circ}(\mathrm{S})
\end{aligned}
$$

where $\Delta_{\text {solv }} H^{\circ}$ is the enthalpy of solvation and $\Delta_{\text {sol }} H^{\circ}$ is the standard enthalpy of solution.

Figure 1 shows the transfer enthalpy of cyclic ethers from DMF to DMF + MeOH mixtures. For the sake of comparison, the analogous data for solutions in DMF $+\mathrm{W}$ mixtures are also presented in the figure. The transfer enthalpy of cyclic ethers from DMF to DMF $+\mathrm{W}$ mixtures has been calculated using the data of the enthalpy of solution of cyclic ethers in the $\mathrm{DMF}+\mathrm{W}$ mixtures $[23,24]$. As it is seen from the graph, the dissolution enthalpies of cyclic ethers in $\mathrm{DMF}+\mathrm{MeOH}$ mixtures slowly grow from the values in pure DMF to those in pure $\mathrm{MeOH}$. The shape of the $\Delta_{\mathrm{tr}} H^{\circ}=f\left(x_{\mathrm{MeOH}}\right)$ function is almost linear in the case of the crown ethers $(12 \mathrm{C} 4,15 \mathrm{C} 5$ and 18C6). It seems to point at the gradual change of the crown ethers solvation sphere along with the change of the mixed solvent composition. In the case of 1,4-dioxane, the $\Delta_{\mathrm{tr}} H^{\circ}$ exhibits a negative deviations from the additivity with a minimum in the range of high DMF content, what suggests the preferential solvation of the solute by the DMF molecules. The latter conclusion agrees with the results of analysis of the thermochemical properties of solutes in the mixtures of DMF and methanol with organic cosolvents [47].

Methanol molecules are highly associated. It can be assumed that an increase in the methanol content in the mixture reduces the number of hydrogen bonds between DMF molecules and $\mathrm{MeOH}$ molecules and increases the number of $\mathrm{MeOH}$ molecules that are highly associated with each other. Cyclic ether molecules may also form hydrogen bonds with the $\mathrm{MeOH}$ molecules. At high methanol content in the mixture cyclic ether molecules probably disrupt the association of methanol to form hydrogen bonds with the molecules of methanol. Therefore, probably the enthalpy of 


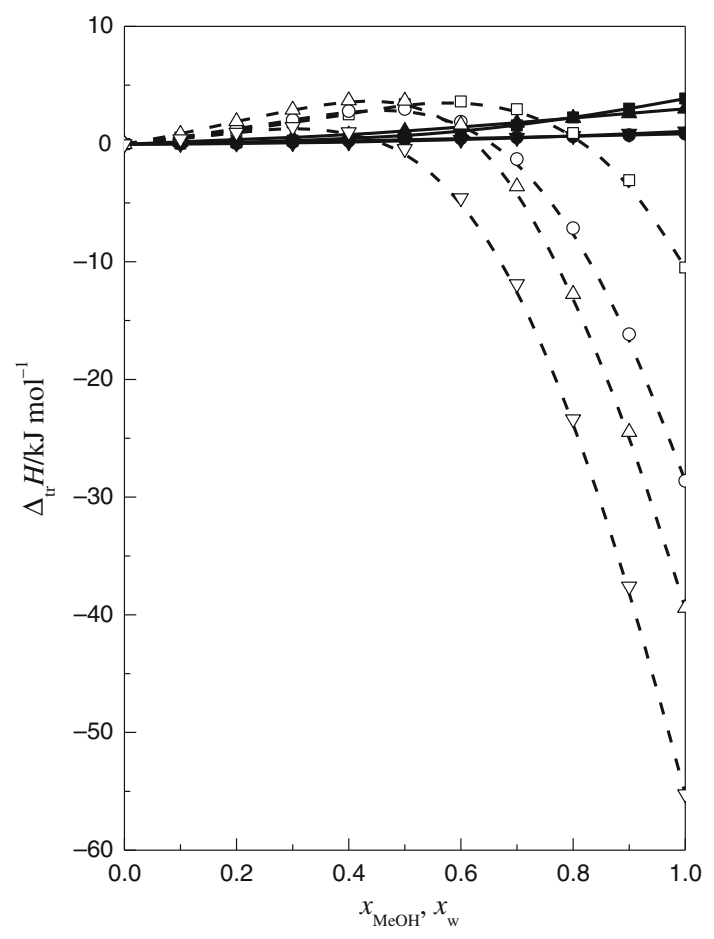

Fig. 1 Transfer enthalpy of cyclic ethers from DMF to $\mathrm{DMF}+\mathrm{MeOH}$ mixture (full symbols) as a function of $x_{\mathrm{MeOH}}$ and from DMF to DMF + W mixtures (open symbols) $[23,24]$ as a function of $x_{\mathrm{w}}: 1,4$ dioxane, filled square; $12 \mathrm{C} 4$, filled circle; $15 \mathrm{C} 5$, filled triangle; and 18C6, filled inverted triangle

dissolution of cyclic ethers increases with increasing the methanol content in DMF $+\mathrm{MeOH}$. It should be stressed that the molecules of cyclic ethers have basic properties due to the free electron pairs on the oxygen atoms and molecules of methanol are characterized by acidic properties. These properties facilitate the interaction of molecules.

The values of the transfer enthalpy function of cyclic ethers in DMF $+\mathrm{W}$ mixtures in the range of high DMF content also grow almost linearly. However, this growth is faster than in the system containing methanol. This is due to a stronger interactions of molecules of DMF with water than with $\mathrm{MeOH}$ ones. The essential differences in the course of $\Delta_{\mathrm{tr}} H^{\circ}=f\left(x_{\mathrm{MeOH}}\right)$ and $\Delta_{\mathrm{tr}} H^{\circ}=f\left(x_{\mathrm{w}}\right)$ curves in the mixtures of $\mathrm{DMF}+\mathrm{MeOH}$ and $\mathrm{DMF}+\mathrm{W}$ are observed in the range of small DMF content, i.e., $x_{\mathrm{MeOH}}>0.5$ and $x_{\mathrm{w}}>0.5$ (Fig. 1). In this area of the mixture of DMF with water, one can observe sharp decrease in the transfer enthalpy of cyclic ethers. The deviations from the additivity of cyclic ethers dissolution enthalpies, $H^{\mathrm{E}}$, are positive in these mixtures. Such behavior is characteristic for the hydrophobic hydration of the solute [27, 28], and it is not observed in the mixture of DMF with $\mathrm{MeOH}$ in the high methanol content area. Thus, the replacement of water with $\mathrm{MeOH}$ in the mixture with
DMF results in a change in the interactions between the solute molecules and molecules of the mixed solvent components.

Using the data of the solution enthalpy of cyclic ethers under investigation, we made the assessment of the effect of the acid-base properties of $\mathrm{DMF}+\mathrm{MeOH}$ on the enthalpy of solution of cyclic ethers in this mixture. For characterization of the Lewis basicity of the solvent, we have used the Kamlet-Taft parameter $B_{\mathrm{KT}}$, while the Lewis acidity has been expressed by the standardized DimrothReichardt parameter $E_{\mathrm{T}}^{\mathrm{N}}$. The values of $B_{\mathrm{KT}}$ for $\mathrm{DMF}+\mathrm{MeOH}$ mixtures have been taken from the literature [48]. The values of $E_{\mathrm{T}}^{\mathrm{N}}$ have been calculated on the base of the appropriate literature data of the Dimroth-Reichardt $E_{\mathrm{T}}$ parameter for $\mathrm{DMF}+\mathrm{MeOH}$ mixtures [49] using Eq. (2).

$E_{\mathrm{T}}^{\mathrm{N}}=\left[E_{\mathrm{T}}(\right.$ solvent $\left.)-E_{\mathrm{T}}(\mathrm{TMS})\right] /\left[E_{\mathrm{T}}(\right.$ water $\left.)-E_{\mathrm{T}}(\mathrm{TMS})\right]$

where $E_{\mathrm{T}}$ is the Dimroth-Reichardt parameter and TMS is tetramethylsilane.

The values of $E_{\mathrm{T}}$ for water and TMS have been also taken from the literature $[29,49,50]$, respectively. Figure 2 shows the acid-base properties of the $\mathrm{DMF}+\mathrm{MeOH}$ mixtures as a function of the molar fraction of DMF. For comparison, in Fig. 3, the acid-base properties of the $\mathrm{DMF}+\mathrm{W}$ mixture, taken from the literature [51], are presented. As can be seen in Figs. 2 and 3, the acid-base properties of the $\mathrm{DMF}+\mathrm{W}$ mixture change in more significant way than those in $\mathrm{DMF}+\mathrm{MeOH}$.

We have found that the enthalpy of dissolution of cyclic ethers linearly depends on the basic properties of $\mathrm{DMF}+\mathrm{MeOH}$ mixtures expressed by the Kamlet-Taft parameter $B_{\mathrm{KT}}$. The inclusion of the Lewis acidity term into the correlation equation did not improve the statistical goodness of fit. Hence, the examined enthalpies of solution of the examined ethers in $\mathrm{DMF}+\mathrm{MeOH}$ mixtures can be presented as a linear function of $B_{\mathrm{KT}}$ (Eq. 3) [19].

$\Delta_{\text {sol }} H^{\circ}=Q_{\circ}+b B_{\mathrm{KT}}$

where $Q_{\mathrm{o}}$ is the value of the given property in the absence of the solvent effect and $b$ indicates the contribution of the base properties to the variation of the enthalpy of solution.

The obtained values of parameters of the relationship (3) are given in Table 3. It comes out from these results that the changes in the solvent Lewis basicity explain almost entirely observed variation of the enthalpy of solution of the cyclic ethers in the system $\left(r^{2}>0.95\right)$. The effect of solvent acidity seems to be insignificant, or it has a constant value and does not influence the variation of the $\Delta_{\text {sol }} H^{\circ}$ values. In the latter case, its value is included into the $Q_{\text {o }}$ parameter value. The negative values of the 


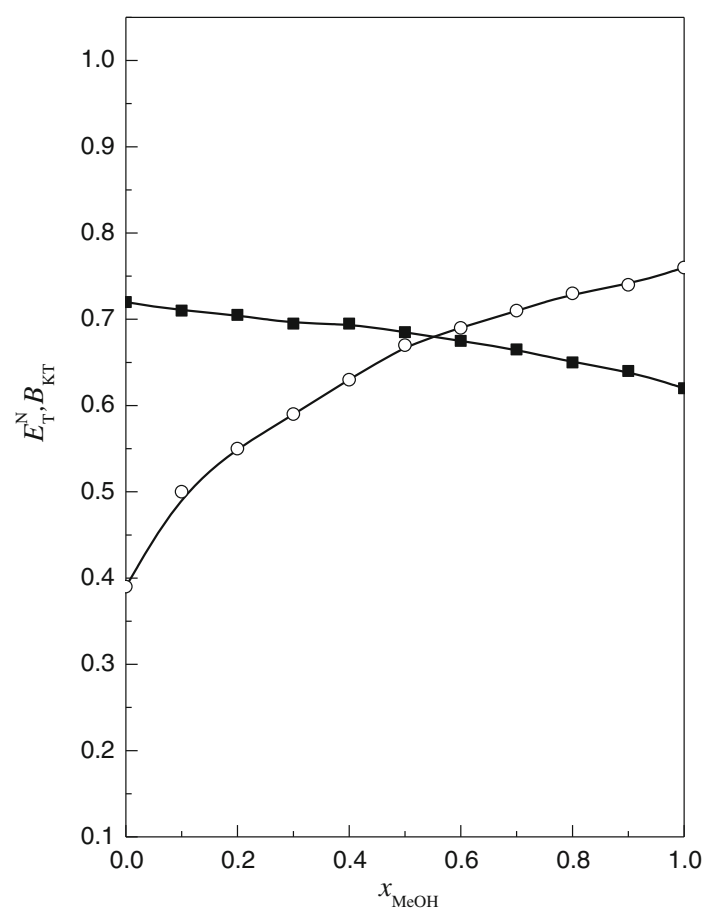

Fig. 2 Acid $\left(E_{\mathrm{T}}^{\mathrm{N}}\right.$, open circle $)$ and base $\left(B_{\mathrm{KT}}\right.$, filled square $)$ properties of DMF + MeOH mixtures as a function of $x_{\mathrm{MeOH}}$ at $298.15 \mathrm{~K}$ (see the text)

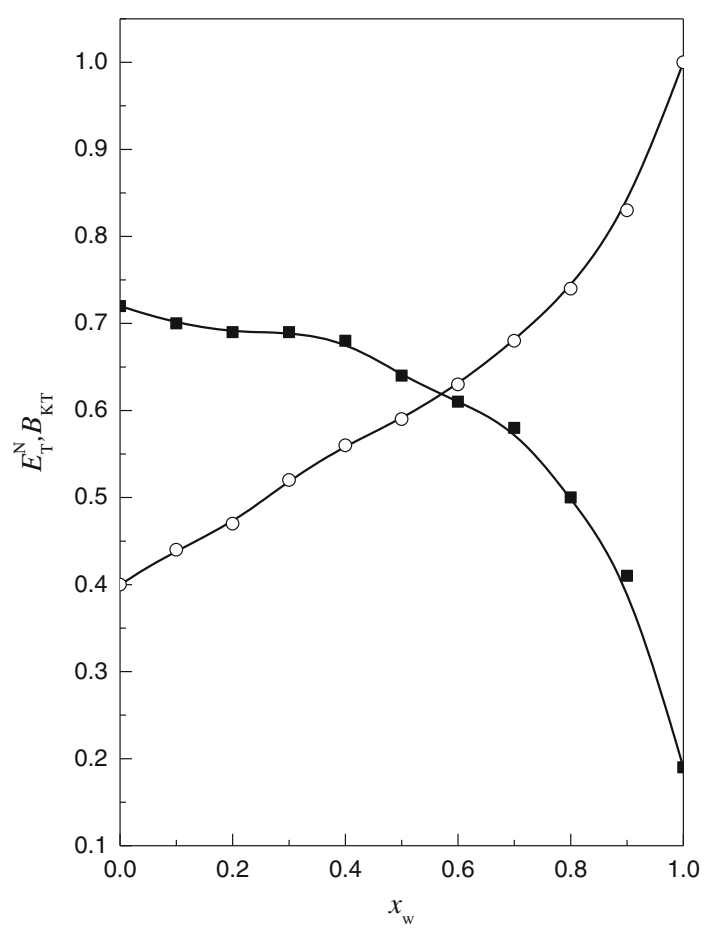

Fig. 3 Acid $\left(E_{\mathrm{T}}^{\mathrm{N}}\right.$, open circle $)$ and base ( $B_{\mathrm{KT}}$, filled square $)$ properties of DMF + W mixtures as a function of $x_{\mathrm{w}}$ at $298.15 \mathrm{~K}$ [51]
Table 3 Values of parameters of Eq. (3): the value of the given property in the absence of the solvent effect $\left(Q_{\mathrm{o}} / \mathrm{kJ} \mathrm{mol}^{-1}\right)$, the contribution of the base properties $(b)$ to the variation of the enthalpy of solution $\left(\Delta_{\mathrm{sol}} H^{\circ}\right)$ of cyclic ethers in DMF $+\mathrm{MeOH}$ mixtures at $298.15 \mathrm{~K}$

\begin{tabular}{lrrl}
\hline & \multicolumn{1}{c}{$Q_{\mathrm{o}} / \mathrm{kJ} \mathrm{mol}^{-1}$} & \multicolumn{1}{l}{$b$} & \multicolumn{1}{l}{$R^{2}$} \\
\hline 1,4-Dioxane & $29.83 \pm 1.78$ & $-40.92 \pm 2.62$ & 0.96454 \\
$12 \mathrm{C} 4$ & $6.57 \pm 0.34$ & $-9.64 \pm 0.51$ & 0.97568 \\
$15 \mathrm{C} 5$ & $22.95 \pm 0.79$ & $-32.51 \pm 1.16$ & 0.98868 \\
$18 \mathrm{C} 6$ & $41.94 \pm 0.39$ & $-11.69 \pm 0.58$ & 0.97630 \\
\hline
\end{tabular}

\pm Standard deviation

$R$ is the regression coefficient

$b$ coefficients in Eq. (3) mean that the effect of dissolution becomes more negative, i.e., energetically more favorable when the Lewis basicity of the solvent grows. It is so, despite the fact that methanol molecules are able to form hydrogen bonds with molecules of the ether. It is also possible that the molecules of methanol form H-bonds predominantly with DMF but not with the ether ones.

Using the determined values of $Q_{\mathrm{o}}$ and $b$ parameters, we recalculated the enthalpy of solution of cyclic ethers and the obtained data are shown in Fig. 4. As it is seen, only a slight deviation of the enthalpy of solution calculated by the use of Eq. (3) from the data obtained experimentally can be observed. It is particularly visible at $x_{\mathrm{MeOH}} \approx 0.3$. This is due to the slight collapse of the curve: $B_{\mathrm{KT}}=f\left(x_{\mathrm{MeOH}}\right)$ within this range of mixed solvent composition (Fig. 2). The very good agreement between measured and calculated values of the $\Delta_{\text {sol }} H^{\circ}$ confirms additionally the above suggestions.

As was shown previously, there are the clear differences between the shapes of curves of the enthalpy of solution of cyclic ethers in mixtures $\mathrm{DMF}+\mathrm{MeOH}$ and $\mathrm{DMF}+\mathrm{W}$ caused by the hydrophobic hydration of cyclic ethers within the range of high water content. Therefore, we decided to verify how the replacement of methanol with water in the mixture with DMF is reflected in the effect of the acid-base properties of the mixture on the enthalpy of solution of cyclic ethers.

It appeared that the dissolution enthalpies of the examined cyclic ethers in DMF $+\mathrm{W}$ mixtures correlate linearly neither with the mixed solvent basicity expressed by the $B_{\mathrm{KT}}$ nor with the solvent acidity expressed by the $E_{\mathrm{T}}^{\mathrm{N}}$ parameter individually. In order to correlate the examined enthalpies of solution, it was necessary to use both the above-mentioned parameters and the analysis has been carried out using Eq. (4) [30].

$\Delta_{\mathrm{sol}} H^{\circ}=Q_{\mathrm{o}}+a E_{\mathrm{T}}^{\mathrm{N}}+b B_{\mathrm{KT}}$ 


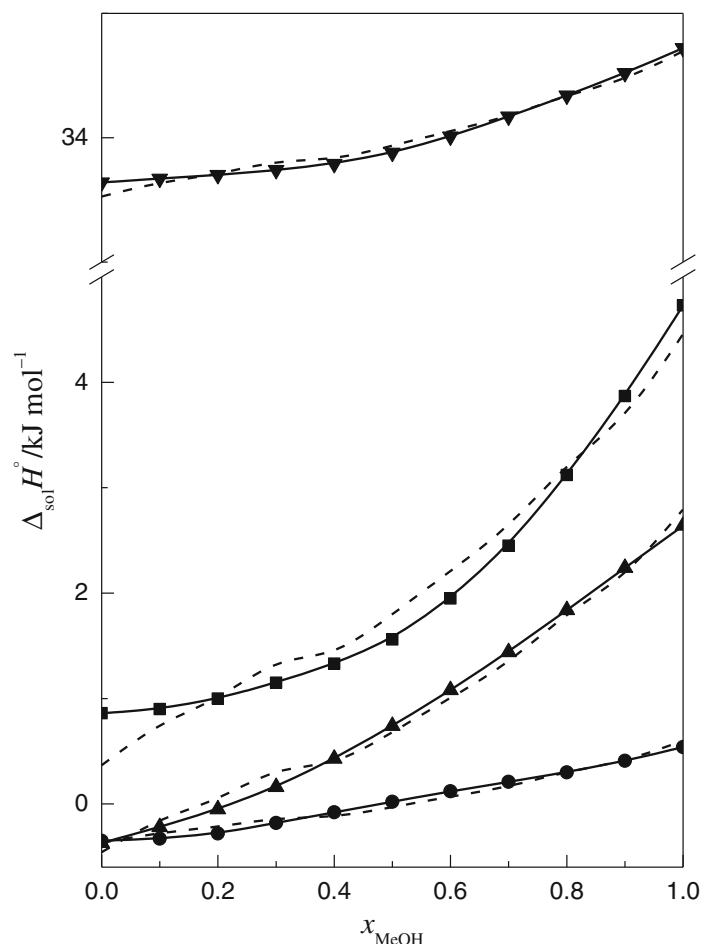

Fig. 4 Standard enthalpy of solution of cyclic ethers in $\mathrm{DMF}+\mathrm{MeOH}$ mixtures at $298.15 \mathrm{~K}$ as a function of $x_{\mathrm{MeOH}}: 1,4$ dioxane, filled square; 12C4, filled circle; 15C5, filled triangle; and 18C6, filled inverted triangle. The solid lines are fits to the experimental data, and the dashed lines were calculated using Eq. (3)

where $Q_{\mathrm{o}}$ is the value of the given property in the absence of the solvent effect, $a$ indicates the contribution of the acid properties, and $b$ indicates the contribution of the base properties to the variation of the enthalpy of solution.

From the performed analysis, it follows that in contrast to the earlier discussed system in the mixture of DMF with water both the acidic and basic parameters of the mixture are necessary to fit the dissolution enthalpy data. The values of obtained coefficients in Eq. 4 are collected in Table 4. As it can be seen, the fitting parameters in this mixed solvent differ significantly from those in $\mathrm{DMF}+\mathrm{MeOH}$ mixture. The $Q_{\mathrm{o}}$ coefficients are negative,

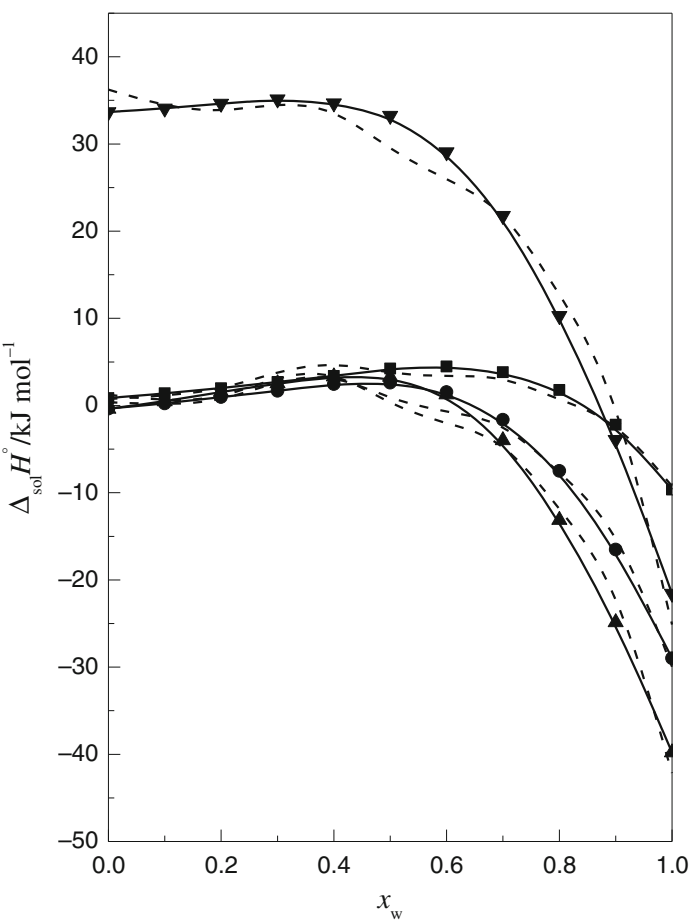

Fig. 5 Standard enthalpy of solution of cyclic ethers in DMF $+\mathrm{W}$ mixtures at $298.15 \mathrm{~K}$ as a function of $x_{\mathrm{w}}: 1,4$ dioxane, filled square; $12 \mathrm{C} 4$, filled circle; 15C5, filled triangle; and 18C6, filled inverted triangle. The solid lines are fits to the experimental data, and the dashed lines were calculated using Eq. (4)

while the $a$ and $b$ coefficients are positive what means that the increase in the both acidic and basic properties of the mixture brings unfavorable contributions to the dissolution enthalpy of the examined solutes. These differences come out from the specific properties of water and its ability to hydrophobic hydration of nonpolar fragments of the organic molecules. This effect is probably included into the $Q_{\text {o value. If so, the energetically unfavorable contributions }}$ to variation of the cyclic ethers dissolution enthalpies illustrate a weakening of the hydrophobic hydration effect and seem to be connected with the destruction of the hydrophobic hydration shells. Table 4 shows also the percentage contribution of acid properties $(\bar{a})$ of $\mathrm{DMF}+\mathrm{W}$

Table 4 Values of parameters of Eq. (4): the value of the given property in the absence of the solvent effect $\left(Q_{\mathrm{o}}, / \mathrm{kJ}\right.$ mol $\left.{ }^{-1}\right)$, the contribution of the acid properties $(a)$, the contribution of the base properties $(b)$ of DMF $+\mathrm{W}$ to the variation of the enthalpy of solution $\left(\Delta_{\text {sol }} H^{\circ}\right)$ of cyclic ethers in DMF $+\mathrm{W}$ mixtures at $298.15 \mathrm{~K}$

\begin{tabular}{lllrl}
\hline & \multicolumn{1}{c}{$Q_{\mathrm{o}}, / \mathrm{kJ} \mathrm{mol}^{-1}$} & \multicolumn{1}{l}{$b$} & $R^{2}$ & $\bar{a}$ \\
\hline 1,4-Dioxane & $-66.35 \pm 0.27$ & $44.05 \pm 0.42$ & $68.71 \pm 1.88$ & 0.94951 \\
$12 \mathrm{C} 4$ & $-100.43 \pm 0.45$ & $49.02 \pm 0.71$ & $112.79 \pm 0.76$ & 0.97705 \\
$15 \mathrm{C} 5$ & $-123.16 \pm 0.73$ & $53.85 \pm 1.13$ & $142.85 \pm 1.21$ & 0.9705 \\
$18 \mathrm{C} 6$ & $-75.04 \pm 0.91$ & $22.97 \pm 1.41$ & $141.79 \pm 1.51$ & 0.97507 \\
\hline
\end{tabular}

${ }^{ \pm}$Standard deviation assuming constancy of the other parameters

$R$ is the regression coefficient 
mixtures to the total variation of the enthalpy of solution of cyclic ethers. As seen, this contribution decreases with increasing the size of cyclic ethers ring.

The data from Table 4 were then used to calculate the cyclic ether enthalpies of solution. The results obtained are shown in Fig. 5. As is seen the fit is very good, the calculated values of the enthalpy of solution differs only slightly from those obtained experimentally.

The calculated parameters of Eqs. (3) and (4) do not change regularly (Tables 3 and 4). It is not easy to explain this fact. In order to through some light for it, we used the model proposed in our previous papers [18, 52]. The structure of mixed solvent depends on the composition of mixture and on the type and energy of interactions between the mixture components. In our model, we assumed that excess molar volume $V^{\mathrm{E}}$ describes the structural properties and excess molar enthalpy $H^{\mathrm{E}}$ describes mainly the energetic properties but also structural properties since a change in the structure brings about changes in the energetic properties. Both functions describe the deviations of properties of the given mixture from those of an ideal mixture. In previous papers, this model was used to explain the changes in the enthalpic effect of preferential solvation of crown ethers [18] and the change in thermodynamics functions of complex formation crown ethers with sodium

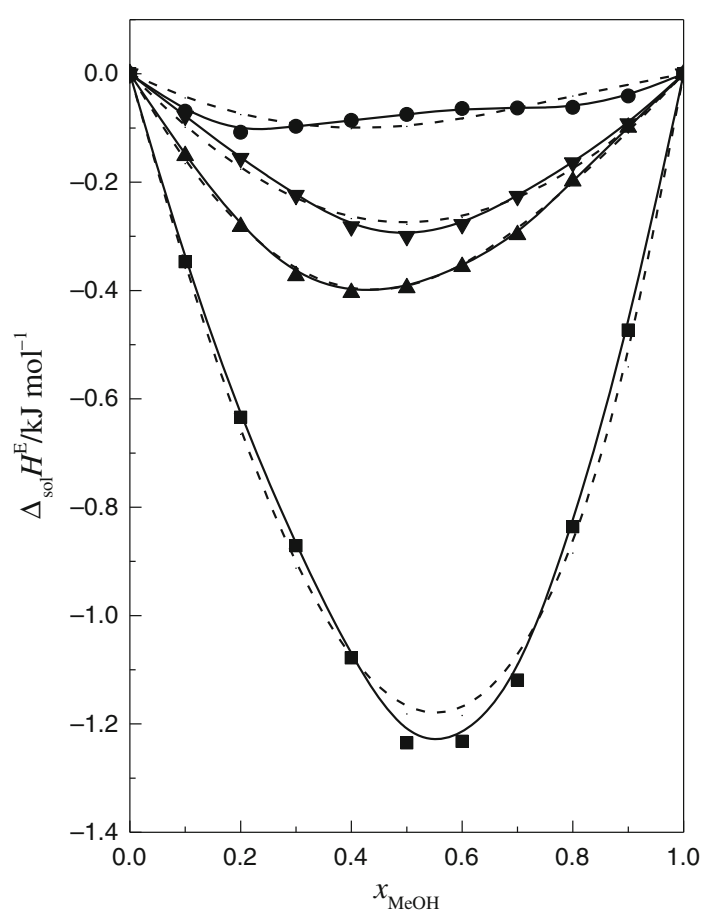

Fig. 6 Deviation from additivity of the enthalpy of solution of cyclic ethers $\left(\Delta_{\text {sol }} H^{\mathrm{E}}\right)$ in DMF $+\mathrm{MeOH}$ mixtures at $298.15 \mathrm{~K}$ as a function of $x_{\mathrm{MeOH}}: 1,4$ dioxane, filled square; $12 \mathrm{C} 4$, filled circle; $15 \mathrm{C} 5$, filled triangle; and 18C6, filled inverted triangle. The solid lines are fits to the experimental data, and the dashed lines were calculated using Eq. (6)
Table 5 Values of parameters of Eq. (6) for cyclic ethers in $\mathrm{DMF}+\mathrm{MeOH}$ mixtures at $298.15 \mathrm{~K}$

\begin{tabular}{lrll}
\hline & \multicolumn{1}{l}{$c$} & \multicolumn{1}{l}{$d$} & $R^{2}$ \\
\hline 1,4-Dioxane & $2.078 \pm 0.120$ & $1.802 \pm 0.430$ & 0.99157 \\
12C4 & $-0.003 \pm 0.058$ & $0.741 \pm 0.206$ & 0.66896 \\
$15 \mathrm{C} 5$ & $0.179 \pm 0.021$ & $2.391 \pm 0.076$ & 0.99759 \\
$18 \mathrm{C} 6$ & $0.326 \pm 0.044$ & $0.987 \pm 0.158$ & 0.97997 \\
\hline
\end{tabular}

${ }^{ \pm}$Standard deviation

$R$ is the regression coefficient

cation with the change of mixed water-organic solvent composition [52]. In the presented paper, we decided to use this model to describe the enthalpy of solution of cyclic ethers. We calculated the deviations from additivity of the solution enthalpy of cyclic ethers using Eq. (5).

$$
\begin{aligned}
& \Delta_{\mathrm{sol}} H^{\mathrm{E}}(\mathrm{DMF}+\mathrm{Y})=\Delta_{\mathrm{sol}} H^{\circ}(\mathrm{DMF}+\mathrm{Y}) \\
& \quad-\left[\left(1-x_{\mathrm{DMF}}\right) \Delta_{\mathrm{sol}} H^{\circ}(\mathrm{Y})+x_{\mathrm{DMF}} \Delta_{\mathrm{sol}} H^{\circ}(\mathrm{DMF})\right]
\end{aligned}
$$

where $\Delta_{\mathrm{sol}} H^{\mathrm{E}}(\mathrm{DMF}+\mathrm{Y})$ is the deviation from additivity of the solution enthalpy of cyclic ethers in the mixtures of $\mathrm{Y}(\mathrm{MeOH}$ or $\mathrm{W})$ with $\mathrm{DMF}, \Delta_{\mathrm{sol}} H^{\circ}(\mathrm{DMF}+\mathrm{Y})$, $\Delta_{\text {sol }} H^{\circ}(\mathrm{Y}), \Delta_{\text {sol }} H^{\circ}(\mathrm{DMF})$ are the standard solution enthalpy of cyclic ethers in the mixtures of $\mathrm{Y}(\mathrm{MeOH}$ or $\mathrm{W})$ with

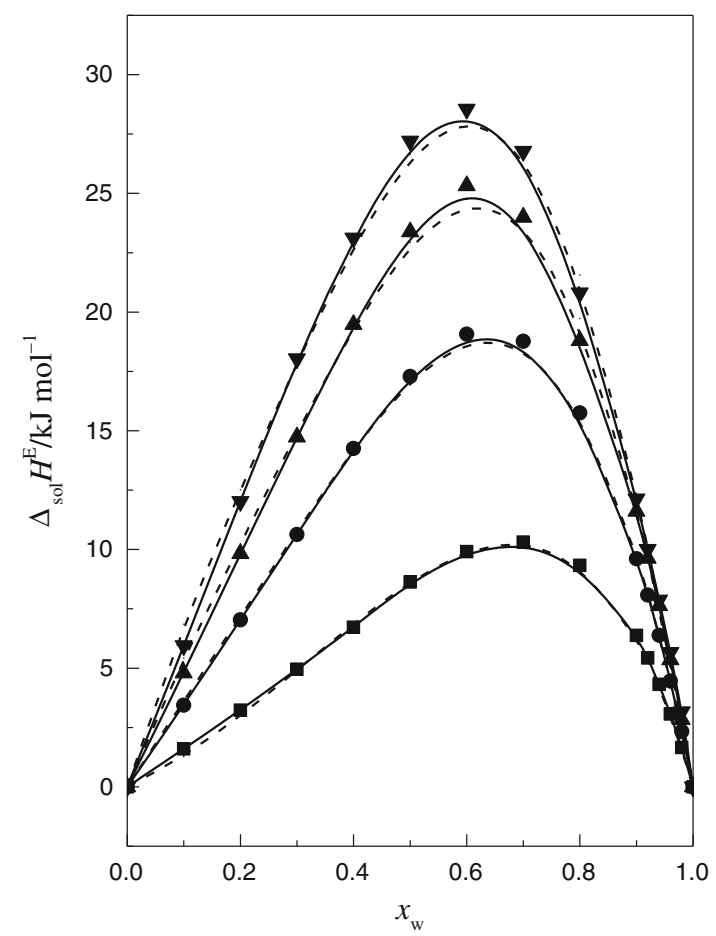

Fig. 7 Deviation from additivity of the enthalpy of solution of cyclic ethers $\left(\Delta_{\text {sol }} H^{\mathrm{E}}\right)$ in DMF $+\mathrm{W}$ mixtures at $298.15 \mathrm{~K}$ as a function of $x_{\mathrm{w}}$ : 1,4 dioxane, filled square; $12 \mathrm{C} 4$, filled circle; $15 \mathrm{C} 5$, filled triangle; and 18C6, filled inverted triangle. The solid lines are fits to the experimental data, and the dashed lines were calculated using Eq. (6) 
Table 6 Values of parameters of Eq. (6) for cyclic ethers in $\mathrm{DMF}+\mathrm{W}$ mixtures at $298.15 \mathrm{~K}$

\begin{tabular}{lrrl}
\hline & \multicolumn{1}{l}{$c$} & \multicolumn{1}{l}{$d$} & $R^{2}$ \\
\hline 1,4-Dioxane & $3.399 \pm 0.285$ & $-6.289 \pm 0.143$ & 0.99820 \\
12C4 & $-3.006 \pm 0.236$ & $-7.033 \pm 0.119$ & 0.99966 \\
15C5 & $-9.189 \pm 0.794$ & $-6.512 \pm 0.400$ & 0.99776 \\
18C6 & $-15.464 \pm 0.882$ & $-4.901 \pm 0.444$ & 0.99790 \\
\hline
\end{tabular}

${ }^{ \pm}$Standard deviation

$R$ is the regression coefficient

DMF, in pure solvent $\mathrm{Y}$ and in pure DMF, respectively, and $x_{\mathrm{DMF}}$ is the mole fraction of DMF in the mixture $\mathrm{DMF}+\mathrm{Y}$.

Then, we described the obtained values of $\Delta_{\mathrm{sol}} H^{\mathrm{E}}(\mathrm{DMF}+\mathrm{Y})$ as a linear combination of the $V^{\mathrm{E}}$ and $H^{\mathrm{E}}$ of the mixed solvent $(\mathrm{DMF}+\mathrm{Y})(\mathrm{Eq} .6)$.

$\Delta_{\mathrm{sol}} H^{\mathrm{E}}(\mathrm{DMF}+\mathrm{Y})=\mathrm{c} V^{\mathrm{E}}+\mathrm{d} H^{\mathrm{E}}$

where $V^{\mathrm{E}}$ and $H^{\mathrm{E}}$ are the excess molar volume and excess molar enthalpy of the mixtures $\mathrm{DMF}+\mathrm{MeOH}$ or
$\mathrm{DMF}+\mathrm{W}$. The factors $\mathrm{c} V^{\mathrm{E}}$ and $\mathrm{d} H^{\mathrm{E}}$ illustrate the contributions of the mentioned earlier properties (i.e., structural and energetic) of the mixed solvent in the total variation of $\Delta_{\text {sol }} H^{\mathrm{E}}(\mathrm{DMF}+\mathrm{Y})$. The results obtained from the Eqs. (5 and 6) are presented on the Figs. 6 and 7.

The values of $V^{\mathrm{E}}$ and $H^{\mathrm{E}}$ for $\mathrm{DMF}+\mathrm{MeOH}$ and $\mathrm{DMF}+\mathrm{W}$ mixtures were taken from the literature [53-56]. The calculated parameter values of Eq. (6) are presented in Tables 5 and 6. As shown in Tables 5 and 6, the calculated parameters of Eq. (6) do not change regularly similarly as in the case of parameters of Eqs. (3) and (4). In Figs. 8 and 9, the contribution of structural $\left(\mathrm{c} V^{\mathrm{E}}\right)$ and energetic $\left(\mathrm{d} H^{\mathrm{E}}\right)$ properties of the mixtures $\mathrm{DMF}+\mathrm{MeOH}$ and $\mathrm{DMF}+\mathrm{W}$ in $\Delta_{\mathrm{sol}} H^{\mathrm{E}}(\mathrm{DMF}+\mathrm{Y})$ is presented. As shown in Fig. 8, the contributions of $\mathrm{c} V^{\mathrm{E}}$ and $\mathrm{d} H^{\mathrm{E}}$ in $\Delta_{\mathrm{sol}} H^{\mathrm{E}}(\mathrm{DMF}+\mathrm{MeOH})$ for 1,4-dioxane are the biggest. The structure of 1,4-dioxane is different than crown ethers: $12 \mathrm{C} 4,15 \mathrm{C} 5$ and $18 \mathrm{C} 6$. Due to the presence of $-\mathrm{CH}_{2} \mathrm{CH}_{2}-$ groups in their molecules, crown ethers show some hydrophobic properties. On the other hand, a molecule of crown ether contains oxygen atoms capable of forming hydrogen bonds with solvent molecules which
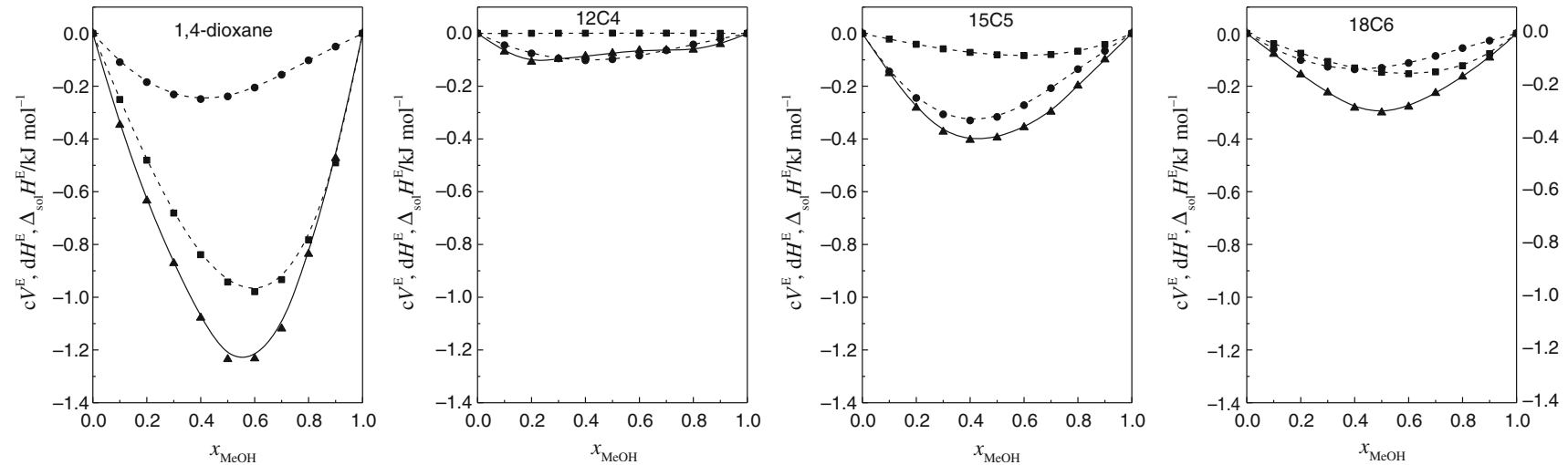

Fig. 8 Graphical illustration of Eq. (6) for the deviation from additivity of the enthalpy of solution of cyclic ethers $\left(\Delta_{\text {sol }} H^{\mathrm{E}}\right)$ in $\mathrm{DMF}+\mathrm{MeOH}$ mixture at $298.15 \mathrm{~K}: \mathrm{c} V^{\mathrm{E}}$, filled square; $\mathrm{d} H^{\mathrm{E}}$, filled circle; $\Delta_{\mathrm{sol}} H^{\mathrm{E}}$, filled triangle
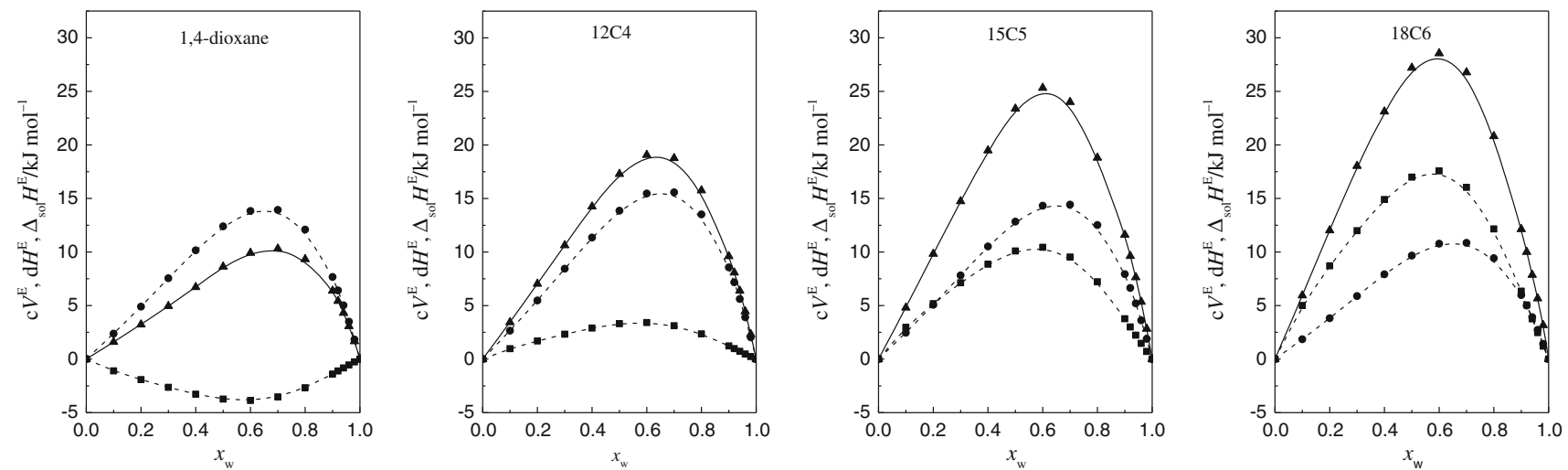

Fig. 9 Graphical illustration of Eq. (6) for the deviation from additivity of the enthalpy of solution of cyclic ethers $\left(\Delta_{\text {sol }} H^{\mathrm{E}}\right)$ in DMF + W mixture at $298.15 \mathrm{~K}: \mathrm{c} V^{\mathrm{E}}$, filled square; $\mathrm{d} H^{\mathrm{E}}$, filled circle; $\Delta_{\mathrm{sol}} H^{\mathrm{E}}$, filled triangle 
show proton donor properties. In the case of 1,4-dioxane, the oxygen atoms are directed outward. Hence, the interactions of the exposed oxygen atoms with the molecules of the mixed solvent will be stronger than in the case of molecules of crown ethers. As can be seen in Fig. 8, the contribution of structural properties $\left(\mathrm{c} V^{\mathrm{E}}\right)$ clearly increases with increasing the crown ethers ring $(12 \mathrm{C} 4,15 \mathrm{C} 5$ and 18C6). The building into the existing structure of the mixed solvent $(\mathrm{DMF}+\mathrm{MeOH})$ increasing ring crown ether causes an increase in the contribution of structural properties $\left(\mathrm{cV}^{\mathrm{E}}\right)$. This is not observed in the case of contribution of energetic properties $\left(\mathrm{d} H^{\mathrm{E}}\right)$. This would suggest similar character of interactions between the molecules of crown ethers and molecules of mixed solvent. In the case of 18C6, the contributions of structural properties $\left(\mathrm{c} V^{\mathrm{E}}\right)$ and energetic properties $\left(\mathrm{d} H^{\mathrm{E}}\right)$ are almost the same. This may be due to changes in conformation of 18C6 with respect to $12 \mathrm{C} 4$ and $15 \mathrm{C} 5$. 18C6 ring is large and flexible, whereas smaller rings $12 \mathrm{C} 4$ and $15 \mathrm{C} 5$ are less flexible and less susceptible to a conformational change.

Although the contributions of structural properties $\left(\mathrm{c} V^{\mathrm{E}}\right)$ and energetic properties $\left(\mathrm{d} H^{\mathrm{E}}\right)$ in $\Delta_{\mathrm{sol}} H^{\mathrm{E}}(\mathrm{DMF}+\mathrm{W})$ (Fig. 9) are much higher than in $\Delta_{\mathrm{sol}} H^{\mathrm{E}}(\mathrm{DMF}+\mathrm{MeOH})$ (Fig. 8), it is possible to observe a similar increase in structural properties with an increase in the ring of the cyclic ether (1,4-dioxane, 12C4, 15C5 and 18C6). In this case, this is due to the hydrophobic hydration of cyclic ethers. This fact confirms the relationship $c V^{\mathrm{E}}$ in maximum as a function of enthalpic effect of hydrophobic hydration of cyclic ethers $(H b(\mathrm{~W}))$ [23, 24] (Eq. 7).

$\mathrm{c} V_{\max }^{\mathrm{E}}=-12.533( \pm 1.892)-0.483( \pm 0.0435) H b(\mathrm{~W})$

$R^{2}=0.98404$

Based on the analysis made, it can be stated that the replacement of methanol with water in the mixture with DMF exerts a great effect on the enthalpy of solution of cyclic ethers as well as on the contribution of structural properties.

\section{Conclusions}

The dissolution enthalpies of the examined cyclic ethers in the mixtures of DMF both with methanol and with water can be presented as a function of the acid-base as well as structural-energetic properties of the mixed solvents. However, in the mixtures with methanol the basic properties of the solvent expressed through the Kamlet-Taft $B_{\mathrm{KT}}$ basicity parameter explain almost totally the observed variation of the dissolution enthalpy of the cyclic ethers in the mixtures, whereas in aqueous mixtures both the acidic and basic parameters are necessary for such analysis. That is as in the DMF $+\mathrm{W}$ mixtures in the range of low DMF content the properties of water are dominating, and its both acid and basic properties exert comparable effect on the enthalpy of solution of cyclic ethers in the mixtures. In both mixtures $(\mathrm{DMF}+\mathrm{MeOH}$ and $\mathrm{DMF}+\mathrm{W})$, the contribution of structural properties in the deviation from additivity of the enthalpy of solution of cyclic ethers increases with increasing the crown ethers ring size and this dependence manifests itself to larger extent in $\mathrm{DMF}+\mathrm{W}$ mixtures. It is closely related to the strong effect of hydrophobic hydration of the cyclic ethers in aqueous mixtures.

Open Access This article is distributed under the terms of the Creative Commons Attribution 4.0 International License (http://crea tivecommons.org/licenses/by/4.0/), which permits unrestricted use, distribution, and reproduction in any medium, provided you give appropriate credit to the original author(s) and the source, provide a link to the Creative Commons license, and indicate if changes were made.

\section{References}

1. Izatt RM, Bradshaw JS, Nielsen SA, Lamb JD, Christensen JJ. Thermodynamic and kinetic data for cation-macrocycle interaction. Chem Rev. 1985;85:271-339.

2. Izatt RM, Pawlak K, Bradshaw JS, Bruening RL. Thermodynamic and kinetic data for macrocycle interaction with cations and anions. Chem Rev. 1991;91:1721-2085.

3. Izatt RM, Bradshaw JS, Pawlak K, Bruening RL, Tarbet BJ. Thermodynamic and kinetic data for macrocycle interaction with neutral molecules. Chem Rev. 1992;92:1261-354.

4. Usacheva TR, Pham Thi L, Terekhova IV, Kumeev RS, Sharnin VA. Application of isothermal titration calorimetry for evaluation of water-acetone and water-dimethylsulfoxide solvent influence on the molecular complex formation between 18-crown-6 and triglycine at $298.15 \mathrm{~K}$. J Therm Anal Calorim. 2015;121:975-81.

5. Zarafu I, Badea M, Ioniţã G, Ioniţã P, Pãun A, Bucur M, Chifiriuc MC, Bleotu C, Olar R. Spectral, magnetic, thermal and biological studies on $\mathrm{Ca}$ (II) and $\mathrm{Cu}$ (II) complexes with a novel crowned Schiff base. J Therm Anal Calorim. doi:10.1007/s10973-016-5573-9.

6. Usacheva TR, Pham Thi L, Terekhova IV, Kumeev RS, Sharnin VA. Thermodynamics of molecular complexation of glycylglycyl-glycine with cryptand [2.2.2] in water-dimethylsulfoxide solvent at 298.15 K. J Therm Anal Calorim. doi:10.1007/s10973016-5383-0.

7. Chen HCh, Chen SH. Diffusion of crown ethers in alcohols. J Phys Chem. 1984;88:5118-21.

8. Linghu X, Bausch CC, Johnson JS. Mechanism and scope of the cyanide-catalyzed cross silyl benzoin reaction. J Am Chem Soc. 2005;127:1833-40.

9. Liu YK, Li R, Yue L, Li BJ, Chen YCh, Wu Y, Ding LS. Unexpected ring-opening reactions of aziridines with aldehydes catalyzed by nucleophilic carbenes under aerobic conditions. Org Lett. 2006;8:1521-4.

10. France S, Wack H, Taggi AE, Hafez AM, Wagerle TR, Shah MH, Dusich CL, Lectka T. Catalytic, asymmetric $\alpha$-chlorination of acid halides. J Am Chem Soc. 2004;126:4245-55.

11. Katritzky AR, Rees ChW, Scriven EFV. Comprehensive heterocyclic chemistry II. A review of the literature 1982-1995. Newkome GR, Pergamon, FL, USA, 1996;9:1-1146. 
12. Szpakowska M, Nagy OB. Application of the competitive preferential solvation theory to facilitated ion transport through binary liquid membranes. J Phys Chem. 1989;93:3851-4.

13. Chen HCh, Chen SH. Diffusion of crown ethers in alcohols. J Phys Chem. 1984;88:5118-21.

14. Abraham MH, Grellier PL, Abboud JLM, Doherty RM, Taft RW. Solvent effects in organic chemistry-recent developments. Can J Chem. 1988:66:2673-96.

15. Castronuovo G, Niccoli M. Solvent effects on the complexation of 1-alkanols by parent and modified cyclodextrins, Calorimetric studies at 298 K. J Therm Anal Calorim. 2011;103:641-6.

16. Heter G, Marcus Y, Waghorne WE. Enthalpies and entropies of transfer of electrolytes and ions form water to mixed aqueous organic solvents. Chem Rev. 2002;102:2773-836.

17. Marcus Y. Gibbs energies of transfer of anions from water to mixed aqueous organic solvents. Chem Rev. 2007;107:3880-97.

18. Jóźwiak M. The effect of properties of water-organic solvent mixtures on the solvation enthalpy of 12-crown-4, 15-crown-5, 18-crown-6 and benzo-15-crown-5 ethers at $298.15 \mathrm{~K}$. Thermochim Acta. 2004;417:31-41.

19. Jóźwiak M, Piekarski H. Thermochemical behaviour of crown ethers aqueous organic solvents. Part IV: propanol and acetonitrile with water mixtures. J Thermal Anal Calorim. 2002;69:291-300.

20. Jóźwiak M. Effect of base-acid properties of the mixture of water with propan-1-ol on the solution enthalpy of cyclic ethers in this mixture at $\mathrm{T}=298.15 \mathrm{~K}$. J Chem Eng Data. 2011;56:4710-4.

21. Jóźwiak M. Thermochemical behaviour of crown ethers in the mixtures of water with organic solvents. Part IX. Effect of baseacid properties of $(1-\mathrm{x}) \mathrm{AN}+\mathrm{xH} 2 \mathrm{O}$ on the solution enthalpy of cyclic ethers in this mixed solvent at $\mathrm{T}=298.15 \mathrm{~K}$. J Chem Thermodyn. 2009;41:522-4.

22. Jóźwiak M. The effect of carbonyl carbon atom replacement in acetone molecule (ACN) by sulphur atom (DMSO) Part III. Effect of base-acid properties of the mixtures of water with acetone or dimethylsulfoxide on the solution enthalpy of cyclic ethers in mixed solvent. J Therm Anal Calorim. 2010;101:1039-45.

23. Jóźwiak M, Kosiorowska MA. Effect of temperature on the process of hydrophobic hydration. Part I. Hydrophobic hydration of 1,4-dioxane and 12-crown-4 ethers. J Chem Eng Data. 2010;55:2776-80.

24. Jóźwiak M, Kosiorowska MA, Wasiak M. Effect of temperature on the process of hydrophobic hydration. Part II. Hydrophobic hydration of 15-crown-5 and 18-crown-6 ethers. J Chem Eng Data. 2010;55:5138-43.

25. Jóźwiak M. Thermal behaviour of crown ethers in the mixtures of water with organic solvents. Part VIII. Hydrophobic hydration and preferential solvation of 1,4-dioxane in $(1-\mathrm{x})$ amide $+\mathrm{H} 2 \mathrm{O}$ at $\mathrm{T}=298.15 \mathrm{~K}$. J Chem Thermodyn. 2007;39:433-7.

26. Jóźwiak M, Madej-Kiełbik L, Piekarski H. Effect of temperature on the solvation of 15-crown-5 ether in water-methanol mixtures. Thermochim Acta. 2012;533:22-7.

27. de Visser C, Somsen G. Hydrophobic interactions in mixtures of DMF and water. Model calculation and enthalpies of solution. J Phys Chem. 1974;78:1719-22.

28. Heuvesland WJM, de Visser C, Somsen G. Hydrophobic hydration of tetraalkylammonium bromides in mixtures of water and some aprotic solvents. J Phys Chem. 1978;82:29-32.

29. Krygowski TM, Fawcett WR. Complementary Lewis acid-base description of solvent effects. I. Ion-ion and ion-dipole interactions. J Am Chem Soc. 1975;97:2143-8.

30. Fawcett WR, Krygowski TM. Complementary Lewis acid-base description of solvent effects. II. Dipole-dipole interactions. Aust J Chem. 1975;28:2115-24.

31. Fawcett WR, Krygowski TM. A characteristic vector analysis of solvent effects for thermodynamic data. Can J Chem. 1976;54:3283-92.
32. Wrona PK, Krygowski TM, Galus Z. Correlation between empirical Lewis amid-base solvent parameters of ion solvation. Part II. Acidity parameters of cations and basicity parameters of anions. J Phys Org Chem. 1991;4:439-48.

33. Jóźwiak M, Warczakowska A. Effect of base-acid properties of the mixtures of water with methanol on the solution enthalpy of selected cyclic ethers in this mixture at $298.15 \mathrm{~K}$. J Therm Anal Calorim. 2015;121:765-70.

34. Maryott AA. Electric polarization and association in solution. III. The dipole moments of some alcohols in very dilute benzene solutions. J Am Chem Soc. 1941;63:3079-83.

35. Chan SC, Valleau JP. Ultrasonic study of hydrochloric acid association in $N, N$-dimethylformamide. Can J Chem. 1968;46:853-8.

36. Piekarski H, Waliszewski D. Hydration effect on urea-non-electrolyte enthalpic pair interaction coefficients. Dissolution enthalpies of urea in aqueous solution of alkoxyethanols at 298.15 K. Thermochim Acta. 1995;258:67-76.

37. Sabbah R, Xu-wu A, Chickos JS, Planas Leitão ML, Roux MV, Torres LA. Reference materials for calorimetry and differential thermal analysis. Thermochim Acta. 1999;331:93-204.

38. Wadsö I, Goldberg RN. Standards in isothermal microcalorimetry (IUPAC Technical Report). Pure Appl Chem. 2001;73:1625-39.

39. Pałecz B. The enthalpies of interaction of glycine with some amides and ureas in water at $25^{\circ} \mathrm{C}$. J Solut Chem. 1995;24:537-50.

40. Desnoyers JE, Perron G, Avedikian L, Morel JP. Enthalpies of the urea-tert-butanol-water system at $25{ }^{\circ} \mathrm{C}$. J Solut Chem. 1976;5:631-44.

41. Egan EP Jr, Luff BB. Heat of solution, heat capacity, and density of aqueous urea solutions at $25^{\circ} \mathrm{C}$. J Chem Eng Data. 1966;11:192-4.

42. Nunes N, Reis M, Moreira L, Elvas-Leitão R. Solution enthalpies of 1,4-dioxane: study of solvent effects through quantitative structureproperty relationships. Thermochim Acta. 2013;574:85-7.

43. Barannikov VP, Guseynov SS, Vyugin AI. Effect of electrostatic interaction on thermochemical behaviour of 12-crown-4 ether in various polar solvents. Thermochim Acta. 2010;499:61-4.

44. Reis M, Nunes N, Elvas-Leitão R, Martins F. Use of quantitative structure-property relationships to study the solvation process of 18-crown-6. Thermochim Acta. 2015;604:140-4.

45. Golikov AN, Kuz'mina IA, Sharnin VA. Thermochemistry of 18-crown-6 ether solvation in binary mixtures of methanol and dimethylformamide. (in russ.) Izv Vyssh Uchebn Zaved Khim Khim Tekhnol. 2007;50:38-40.

46. Kuz'mina IA, Usacheva TR, Sharnin VA, Volkova MA. Thermochemistry of solvation of 18-crown- 6 ether in binary methanol-acetonitrile solvents. Russ J Phys Chem A 2013;87:1076-8.

47. Piekarski H. Thermochemistry of electrolyte solutions. Effect of added cosolvent. J Therm Anal Calor. 2012;108:537-45.

48. Krygowski TM, Reichardt Ch, Wrona PK, Wyszomirska C, Zielkowska U. Empirical parameters of Lewis basicity of binary solvent mixtures. Mixtures with methanol. J Chem Res (S) $1983 ; 116-7$.

49. Mancini PME, Terenzani A, Gasparri MG, Votterc LR. Determination of the empirical polarity parameter $E_{\mathrm{T}}(30)$ for binary solvent mixtures. J Phys Org Chem. 1995;8:617-23.

50. Reichardt Ch, Harbusch-Görnert E. Über Pyridinium-N-phenolatBetaine und ihre Verwendung zur Charakterisierung der Polarität von Lösungsmitteln, X. Liebigs Ann Chem. 1983;721-896.

51. Krygowski TM, Wrona PK, Zielkowska U. Empirical parameters of Lewis acidity and basicity for aqueous binary solvent mixtures. Tetrahedron. 1985;41:4519-27.

52. Jóźwiak M. Complex formation of crown ethers with cations in the (water + organic solvent) mixtures: part IX. Thermodynamics of interactions of $\mathrm{Na}+$ ion with benzo-15-crown-5 ether in $(1-\mathrm{x}) \mathrm{DMA}+\mathrm{xH}_{2} \mathrm{O}$ at $\mathrm{T}=298.15 \mathrm{~K}$. J Chem Thermodyn. 2004;36:1129-38. 
53. Wang C, Li H, Zhu L, Han S. NMR and excess volumes studies in DMF-alcohol mixtures. J Solut Chem. 2002;31:109-17.

54. de Visser C, Perron G, Desnoyers JE, Heuvelsland WJM, Somsen G. Volumes and heat capacities of mixtures of N, N-dimethylformamide and water at $298.15 \mathrm{~K}$. J Chem Eng Data. 1977;22:74-9.
55. Iloukhani $\mathrm{H}$, Zarei HA. Excess molar enthalpies of $\mathrm{N}, \mathrm{N}$ dimethylformamide + alkan-1-ols (C1-C6) at 298.15 K. J Chem Eng Data. 2002;47:195-7.

56. Zaichikov AM, Krestov GA. Thermodynamic properties of water- $N, N$-dimethylformamide system. (in russ). Zh Fiz Khim. 1995;69:389-94. 